\title{
MULTIPLE FORMS OF STAPHYLOCOCCAL ALPHA-TOXIN
}

\author{
A. Christine McNiven, P. Owen and J. P. Arbuthnott* \\ Department of Microbiology, Alexander Stone Building, University of Glasgow, \\ Garscube Estate, Bearsden, Glasgow
}

\section{Plate VIII}

THE method of electrofocusing has been applied successfully to the purification of many proteins. In some instances the technique has revealed the existence of several components each having the same biological activity but a different iso-electric point $(p \mathrm{I})$.

Among the proteins that exhibit multiple forms are several cytolytic bacterial toxins including Clostridium perfringens $\alpha$-toxin (Bernheimer, Grushoff and Avigad, 1968; Smyth and Arbuthnott, 1969; Sugahara and Ohsaka, 1970) and three staphylococcal toxins: $\alpha$-toxin (Wadström, 1968), $\beta$-toxin (Möllby and Wadström, 1970) and $\delta$-toxin (Kreger et al., 1970).

Multiple forms of staphylococcal $\alpha$-toxin were described first by Bernheimer and Schwartz (1963), who used sucrose density gradient electrophoresis. From electrofocusing studies Wadström reported four haemolytic forms, which he designated $\alpha-\mathrm{I}_{\mathrm{a}}(p \mathrm{I} \quad 8 \cdot 0-8 \cdot 7), \alpha-\mathrm{I}_{\mathrm{b}}$

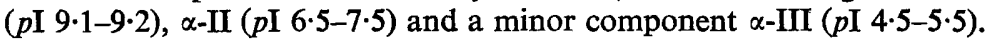

In the present detailed study we found a main component ( $p$ I 8.55 $\pm 0 \cdot 12)$, accounting for 85-95 per cent. of the recovered haemolytic activity, and five minor haemolytic peaks. We decided to assess the relationship between the different components using the following criteria: (a) haemolytic activity against the erythrocytes of different species, $(b)$ quantitative neutralisation of haemolytic activity by standard $\alpha$-antitoxin, and $(c)$ gel-diffusion tests. Peak fractions were refocused in the presence and absence of $6 \mathrm{M}$ urea to determine the extent of " interconversion". The behaviour of the main components in polyacrylamide disk-gel electrophoresis was also investigated.

Electrofocusing studies should clarify the nomenclature of bacterial haemolysins; the existence of multiple forms may account for some of the earlier confusion. Precise definition of toxins and enzymes is necessary in attempting to evaluate the role of these products in pathogenicity. Moreover, where multiple forms have been demonstrated, the isolation of individual components, in a high degree of purity, may allow a reassessment of the role of specific antibodies in experimental infection.

\section{MATERIALS AND METHODS}

Toxin production. Culture supernatant fluid containing staphylococcal $\alpha$-toxin was prepared from strain Wood 46 (NCTC 7121) by the method of Bernheimer and Schwartz. Solid ammonium sulphate was added to a final concentration of 85 per cent. (w/v) and, after overnight standing at $4^{\circ} \mathrm{C}$, the fine precipitate was harvested by filtration through a layer

Received 10 March 1971; accepted 8 June 1971.

* Alan Johnston, Lawrence and Moseley Research Fellow of the Royal Society.

J. MED. MICROBIOL. - VOL. 5 (1972) 
of Hyflo supercel (Hopkin and Williams Co., Essex). The crude toxin was dissolved in onehundredth of the original volume in $0.03 \mathrm{M}$ sodium borate buffer $p \mathrm{H} 8.3$ (28.6 g sodium tetraborate, $\mathrm{Na}_{2} \mathrm{~B}_{4} \mathrm{O}_{7} 10 \mathrm{H}_{2} \mathrm{O}$, and $18.55 \mathrm{~g}$ boric acid, $\mathrm{H}_{3} \mathrm{BO}_{3}$, made up to 1 litre with distilled water); such preparations contained approximately 100,000 haemolytic units (HU) per $\mathrm{ml}$. In order to simplify the procedure and to minimise possible alteration of the toxin due to purification, crude preparations were applied to the isoelectric focusing column immediately after dialysis against 1 per cent. $(\mathrm{w} / \mathrm{v})$ glycine to remove inorganic salts.

Electrofocusing. LKB (LKB-Produkter, Stockholm, Sweden) columns of $110 \mathrm{ml}$ capacity (8101) and of $440 \mathrm{ml}$ capacity (8102) were used with a final concentration of 1 per cent. ( $\mathrm{v} / \mathrm{v})$ carrier ampholytes (LKB Ampholine), having a $p \mathrm{H}$ range of 3-10, in a sucrose density gradient. The central electrode compartment (anode) contained 1 per cent. (v/v) sulphuric acid in 60 per cent. (w/v) sucrose. Dialysed toxin, made 0.5 per cent. $(\mathrm{v} / \mathrm{v})$ with Ampholine, was used as the less dense solution; the dense solution contained 45 per cent. (w/v) sucrose and 1.5 per cent. ( $\mathrm{v} / \mathrm{v})$ Ampholine. The cathode consisting of 1 per cent. (w/v) sodium hydroxide in distilled water was layered on top of the gradient. For preparative purposes up to $100 \mathrm{mg}$ of crude toxin were applied to the 8101 column and up to $800 \mathrm{mg}$ to the 8102 column. In analytical studies of interconversion phenomena as little as $0.74 \mathrm{mg}$ protein was applied to the 8101 column. Each run had a final potential of $800 \mathrm{~V}$ and the period of focusing was from 45 to $66 \mathrm{hr}$ at $5^{\circ} \mathrm{C}$. Fractions of $2 \mathrm{ml}(8101 \mathrm{column})$ and $8 \mathrm{ml}(8102 \mathrm{column})$ were monitored for $p \mathrm{H}$ at $5^{\circ} \mathrm{C}$ with a micro-electrode (Activion, model M $27 \mathrm{DP}$, Kinglassie, Fife) coupled to a Vibret model 46A $p \mathrm{H}$ meter (E.I.L., Richmond, Surrey). Electrofocusing in urea was carried out in the same conditions except that all solutions were made $6 \mathrm{M}$ with respect to urea (Analar grade, BDH, Poole). Removal of Ampholine and concentration of protein were achieved by dialysing the fractions against 85 per cent. (w/v) saturated ammonium

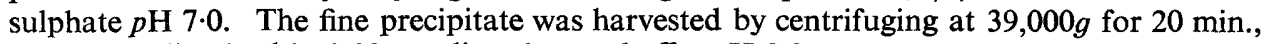
and was redissolved in $0.03 \mathrm{M}$ sodium borate buffer $p \mathrm{H} 8 \cdot 3$.

Haemolytic activity. Phosphate-buffered saline diluent stabilised with $0 \cdot 1$ per cent. (w/v) bovine serum albumin (PBSA) together with 0.7 per cent. suspensions of rabbit erythrocytes (Bernheimer and Schwartz) were used throughout for haemolysis titrations. To screen large numbers of fractions each fraction was diluted 1 in 10,1 in 100 and 1 in 1000 in $0.9 \mathrm{ml}$ amounts of PBSA and an equal volume of erythrocyte suspension added. After $10 \mathrm{~min}$. at $37^{\circ} \mathrm{C}$ the dilution showing complete haemolysis was noted. This enabled us to determine the regions of the column having significant haemolytic activity. The peaks of haemolytic activity were determined by making serial doubling dilutions in $0.5 \mathrm{ml}$ amounts of PBSA and adding $0.5 \mathrm{ml}$ of erythrocyte suspension to each tube. Titrations were incubated for $30 \mathrm{~min}$. at $37^{\circ} \mathrm{C}$ and the 50 per cent. haemolysis end-point was read visually. When greater resolution was necessary dilutions increasing in steps of 30 per cent. were made in 1 -ml amounts of PBSA; after addition of 1-ml amounts of rabbit erythrocyte suspension, the tubes were incubated at $37^{\circ} \mathrm{C}$ for $30 \mathrm{~min}$. and then centrifuged briefly. The 50 per cent. haemolysis end-point was determined spectrophotometrically at $545 \mathrm{~nm}$. Haemolytic activity against human, horse and sheep erythrocytes was assayed by doubling dilution titrations as described above.

Neutralisation tests. A standard antiserum (CPP 76/63, Wellcome Research Laboratories, Beckenham, Kent) was titrated in duplicate: to two sets of doubling dilutions of the antiserum in $0.5 \mathrm{ml}$ amounts of PBSA were added $0.2 \mathrm{ml}$ volumes of PBSA containing 4 and $8 \mathrm{HU}$ of staphylococcal $\alpha$-toxin. After the toxin-antitoxin mixtures had been incubated for $45 \mathrm{~min}$. at $37^{\circ} \mathrm{C}, 0.3 \mathrm{ml}$ of 0.7 per cent. rabbit erythrocyte suspension was added to each tube and the mixtures were incubated for a further $30 \mathrm{~min}$. at $37^{\circ} \mathrm{C}$. The end-point was taken as the last tube in the series showing no haemolysis. A difference of one tube was allowed as experimental error.

Double diffusion tests. Cups of $0.04 \mathrm{ml}$ capacity containing undiluted standard antiserum (CPP 76/63) or test substance were placed at $7 \mathrm{~mm}$ distance on the surface of a 3-mm-thick layer of 1 per cent. Ionagar (Difco) in borate-sodium chloride buffer $(0.03 \mathrm{M}$ sodium borate, $0 \cdot 14 \mathrm{M}$ sodium chloride, $p \mathrm{H} 8 \cdot 3$ ). The plates were incubated at $37^{\circ} \mathrm{C}$ overnight and allowed to stand for 7 days at room temperature. 
Disk-gel electrophoresis. The procedure for electrophoresis in the presence of sodium dodecyl sulphate (SDS) was a modification of the method of Davis (1964). Optimal resolution was obtained with separating gels containing 11.7 per cent. (w/v) acrylamide (BDH, Poole) and 0.153 per cent. (w/v) $\mathrm{NN}^{\prime}$-methylenebisacrylamide (BDH, Poole); stacking gels were mechanically strengthened by a modification of the method of De Vito and Santomé (1966) omitting ethylene diamine tetracetate. The gels and the buffer systems were made $0 \cdot 1$ per cent. (w/v) and the toxin samples $0 \cdot 2$ per cent. (w/v) with SDS. Electrophoresis was performed at $1 \mathrm{~mA}$ per gel until the tracking dye reached the last few millimetres, at which time the current was boosted to $5 \mathrm{~mA}$ per gel. Fixation and staining were carried out overnight in a solution containing 1 per cent. ( $\mathrm{w} / \mathrm{v})$ amido black, 10 per cent. ( $\mathrm{v} / \mathrm{v})$ acetic acid and 50 per cent. $(\mathrm{v} / \mathrm{v})$ methanol. Before the gels were differentiated by electrophoretic destaining, they were rehydrated in 7 per cent. $(v / v)$ acetic acid. $R_{f}$ values were determined by comparison with bromophenol blue. For molecular weight determination, the following marker proteins were run electrophorically under identical conditions: bovine serum albumin (Sigma Chemical Company, St Louis, Missouri, USA), molecular weight = 67,000; ovalbumin (Koch-Light, Colnbrook, Bucks.), molecular weight $=45,000$; yeast hexokinase (Sigma Chemical Company, St Louis, Missouri, USA), molecular weight $=45,000$; bovine pancreatic chymotrypsinogen (Miles-Seravac, Maidenhead, Berks.), molecular weight $=25,000$; sperm whale myoglobin (Koch-Light, Colnbrook, Bucks.), molecular weight $=17,800$; and horse heart cytochrome $c$ (Koch-Light, Colnbrook, Bucks.), molecular weight $=12,400$. The molecular weight of staphylococcal $\alpha$-toxin was determined from a standard curve of the logarithm of molecular weights of these standard proteins against $\mathbf{R}_{\mathbf{f}}$ values (Shapiro, Viñuela and Maizel, 1967). The conditions described by Neville (1967) were used to perform gel electrophoresis in the presence of urea.

Protein. Protein estimations (Lowry et al., 1951) were carried out on samples before electrofocusing, with crystalline bovine serum albumin as standard. After focusing, the protein content of fractions was monitored by ultraviolet extinction measurements at $280 \mathrm{~nm}$ with a Pye Unicam model SP 500 spectrophotometer with cells of $10-\mathrm{mm}$ light-path. The $E_{280}$ of a 1 per cent. (v/v) Ampholine solution was 0.02.

\section{RESULTS}

In a total of 23 determinations the main haemolytic component, accounting for 85-95 per cent. of the recovered haemolytic activity, had a $p \mathrm{I}$ of $8 \cdot 55 \pm 0 \cdot 12$. Up to five additional haemolytic peaks were observed and a typical elution profile is shown in fig. 1. Reading from the acidic end of the $p \mathrm{H}$ gradient, the $p$ I's in this case were $3 \cdot 95,6 \cdot 2,7 \cdot 35,8 \cdot 55,9 \cdot 1$ and $9 \cdot 95$. In terms of the recovered haemolytic activity the components accounted for $1 \cdot 0,1 \cdot 3,4 \cdot 9,87 \cdot 6,4 \cdot 5$ and $1 \cdot 1$ per cent. respectively. At this point it is convenient to designate the components by numbers from 1 to 6 . Table I shows the mean $p I$ determined from experiments in which the components were clearly resolved.

In experiments with ammonium sulphate-precipitated crude staphylococcal $\alpha$-toxin, components 3,4 and 5 were always detected either as separate peaks or as well-defined shoulders; components 1,2 and 6 were found less frequently.

It should be noted that in the $p \mathrm{H}$ region $1 \cdot 0-5 \cdot 5$, a series of brown zones was observed which sometimes contained visible precipitate. Component 1 was associated with one such zone.

\section{Identity of the components}

The identity of each haemolytic component was investigated, with the criteria mentioned previously. Removal of Ampholine and concentration of protein 
in peak fractions was achieved by ammonium sulphate precipitation. The precipitate was dissolved in one-quarter of the original volume of the fraction in $0 \cdot 03 \mathrm{M}$ sodium borate $p \mathrm{H} 8 \cdot 3$. These preparations were tested for haemolytic

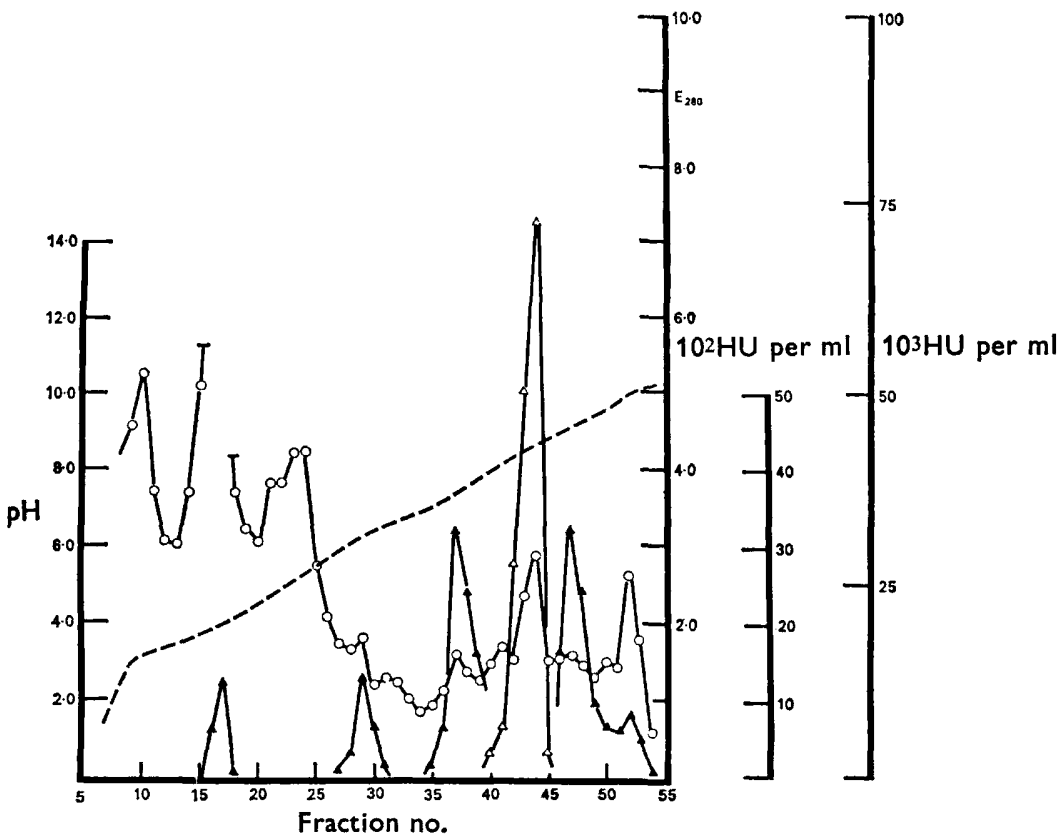

Fig. 1.-Electrofocusing of crude ammonium sulphate-precipitated toxin $(795.0 \mathrm{mg}$ applied to 8102 column) in $p \mathrm{H} 3-10$ gradient. $---p \mathrm{H} ; 0-0$ extinction at $280 \mathrm{~nm} ; \Delta \stackrel{\mathrm{O}}{\longrightarrow}$ haemolytic activity $\left(10^{3} \mathrm{HU}\right.$ per $\left.\mathrm{ml}\right)$;

TABLE I

Iso-electric points ( $p I$ 's) of the haemolytic components separated by electrofocusing

\begin{tabular}{c|c|c}
\hline $\begin{array}{c}\text { Component } \\
\text { number }\end{array}$ & $\begin{array}{c}\text { Number of } \\
\text { determinations }\end{array}$ & $\begin{array}{c}\text { Mean } p \mathrm{I}( \pm \mathrm{SE}) \\
\text { of component }\end{array}$ \\
\cline { 2 - 3 } 1 & 4 & $4 \cdot 32 \pm 0 \cdot 24$ \\
2 & 10 & $6 \cdot 28 \pm 0 \cdot 11$ \\
3 & 6 & $7 \cdot 36 \pm 0 \cdot 03$ \\
4 & 23 & $8 \cdot 55 \pm 0 \cdot 12$ \\
5 & 13 & $9 \cdot 15 \pm 0.07$ \\
6 & 5 & $10 \cdot 01 \pm 0.05$ \\
\hline
\end{tabular}

activity against human, horse, rabbit and sheep erythrocytes. From table II it can be seen that components 3,4 and 5 had the marked specificity for rabbit erythrocytes characteristic of purified staphylococcal $\alpha$-toxin. Components 1 and 6 exhibited less species specificity and component 2 occupied an intermediate position. On the basis of these findings it appeared likely that components 1 and 6 were unrelated to staphylococcal $\alpha$-toxin. 
Neutralisation tests showed that within the experimental error the haemolytic activity of components $2,3,4$ and 5 was quantitatively neutralised by standard $\alpha$ anti-toxin. The activity of components 1 and 6 was not neutralised even at high concentrations of antiserum.

In agar double diffusion tests (fig. $2 a$ and $b$ ) the main line of precipitation obtained with component 4 against $\alpha$ anti-toxin showed a reaction of identity with components 2 and 3 ; a reaction of partial identity was observed with component 5. This further substantiates the view that components $2,3,4$ and 5 represent multiple forms of staphylococcal $\alpha$-toxin. Components 1 and 6 did not show reactions of identity with the main line of precipitation. Indeed, component 6 exhibited a strong reaction of non-identity. These tests also showed that

TABLE II

Spectrum of haemolytic activity of components separated by electrofocusing

\begin{tabular}{|c|c|c|c|}
\hline \multirow{2}{*}{$\begin{array}{l}\text { Component } \\
\text { number }\end{array}$} & \multicolumn{3}{|c|}{$\begin{array}{l}\text { Haemolytic index of component (if } \\
\text { activity against rabbit erythrocytes is } \\
\text { taken as 100) against erythrocytes of }\end{array}$} \\
\hline & $\operatorname{man}$ & horse & sheep \\
\hline $\begin{array}{l}1 \\
2 \\
3 \\
4 \\
5 \\
6\end{array}$ & $\begin{array}{c}200 \\
3 \\
0 \cdot 8 \\
0 \cdot 05 \\
1 \cdot 6 \\
25\end{array}$ & $\begin{array}{c}100 \\
12 \\
1 \cdot 6 \\
0 \cdot 1 \\
1 \cdot 6 \\
12\end{array}$ & $\begin{array}{c}50 \\
6 \\
6 \\
1 \cdot 5 \\
1 \cdot 6 \\
25\end{array}$ \\
\hline
\end{tabular}

although component 4 was highly purified it did give a minor line of precipitation that was shared with components $1,2,3$ and 5 . The significance of this is not yet clear.

By these criteria components 1 and 6 are not related to staphylococcal $\alpha$-toxin and it is now possible to designate the $\alpha$-toxin components. We propose the following nomenclature: $\alpha_{\mathrm{A}}(p \mathrm{I}=8.55 \pm 0.12), \quad \alpha_{\mathrm{B}}(p \mathrm{I}=9 \cdot 15 \pm 0.07)$, $\alpha_{\mathrm{C}}(p \mathrm{I}=7 \cdot 36 \pm 0 \cdot 03)$ and $\alpha_{\mathrm{D}}(p \mathrm{I}=6 \cdot 28 \pm 0 \cdot 11)$.

\section{Refocusing experiments}

High-activity fractions of the $\alpha_{\mathrm{A}}$ component were bulked and refocused on broad gradients $(p \mathrm{H} \mathrm{3-10)}$. Between 2 and $4 \alpha$-toxin components reappeared. The main component was again $\alpha_{A}$, accounting for 65-98 per cent. of the recovered haemolytic activity. Component $\alpha_{\mathrm{B}}$ appeared each time in amounts varying from 2 to 35 per cent. and traces ( $<1$ per cent.) of $\alpha_{\mathrm{C}}$ and $\alpha_{\mathrm{D}}$ were detected. A refocusing experiment showing the formation of $\alpha_{A}$ and $\alpha_{B}$ is shown in fig. 3 . The identity of each component was confirmed using the criteria mentioned above. It should be noted that, when the fraction of $\alpha_{\mathrm{A}}$ having maximum activity (i.e., the peak fraction) was refocused, no detectable amounts of $\alpha_{\mathrm{C}}$ and $\alpha_{\mathrm{D}}$ were found. The $\alpha_{\mathrm{B}}$ component was always present but did not exceed 
5 per cent. of the recovered activity. The converse, namely, the conversion of $\alpha_{B}$ to $\alpha_{A}$, was demonstrated by refocusing a single peak fraction of $\alpha_{B}$ (fig. 4); in this case $\alpha_{\mathrm{B}}$ accounted for 67 per cent. and $\alpha_{\mathrm{A}}$ for 33 per cent. of the recovered activity.

In order to investigate these findings it was decided to refocus $\alpha_{A}$ in the presence of $6 \mathrm{M}$ urea. The $\alpha$-toxin activity was recovered in a single peak having a $p \mathrm{I}$ of 8.50 (fig. 5) confirming that $\alpha_{\mathrm{A}}$ represents the principal form of staphylococcal $\alpha$-toxin. A single peak of activity was also observed when $\alpha_{B}$

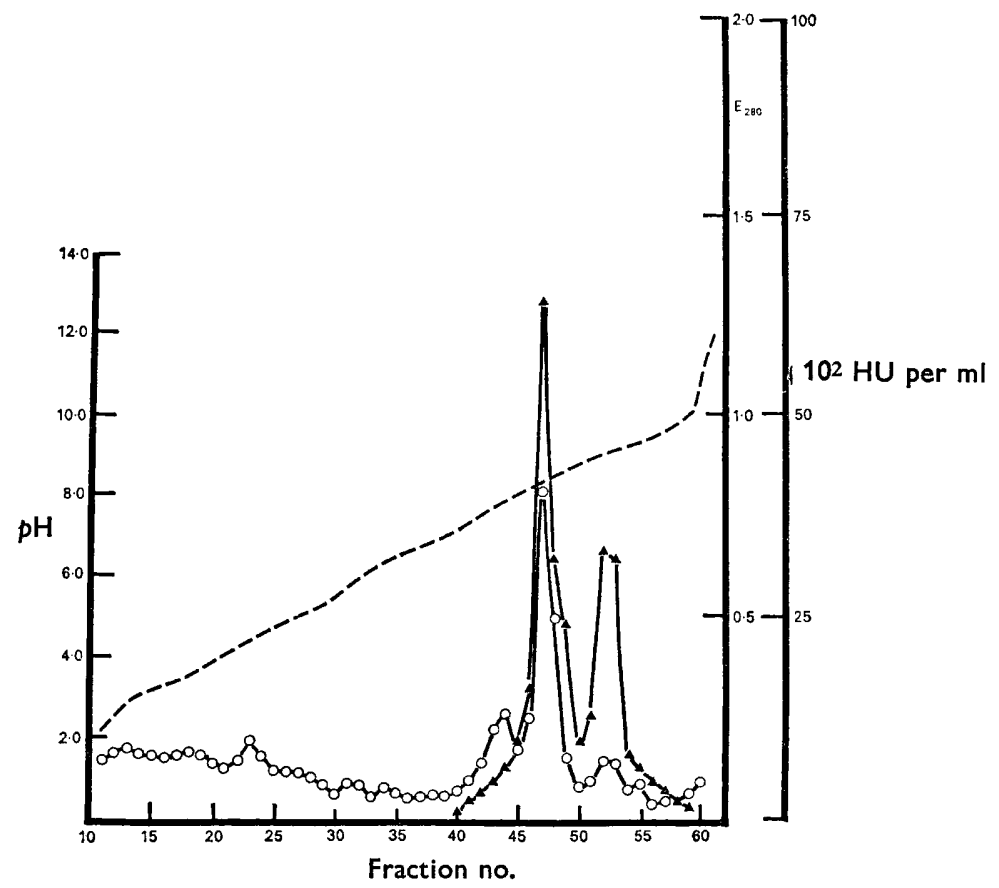

FIG. 3.--Refocusing of the main component $\alpha_{A}(7.0 \mathrm{mg}$ applied to 8101 column) in a $p H$ $3-10$ gradient...$--p \mathrm{H}$; O-O extinction at $280 \mathrm{~nm} ; \Delta-\boldsymbol{\Delta}$ haemolytic activity.

was refocused in $6 \mathrm{M}$ urea. This aspect was studied further by examining the behaviour of $\alpha_{\mathrm{A}}$ and $\alpha_{\mathrm{B}}$ in disk-gel electrophoresis in the presence of SDS and $6 \mathrm{M}$ urea.

\section{Disk-gel electrophoresis}

This technique was used to examine the homogeneity of the $\alpha_{A}$ and $\alpha_{B}$ components. As found previously (Arbuthnott, Freer and Bernheimer, 1967) little protein penetrated the separating gel under standard conditions. In order to solubilise the toxic protein, the dissociating agent SDS was incorporated. Proteins are known to bind SDS in proportion to their molecular weights. The resulting complexes lose charge specificity and migrate solely according to molecular size (Reynolds and Tanford, 1970). When the $\alpha_{A}$ and $\alpha_{B}$ components were run in the SDS system (fig. 6), a band having a molecular weight of 36,000 was observed in both preparations. 


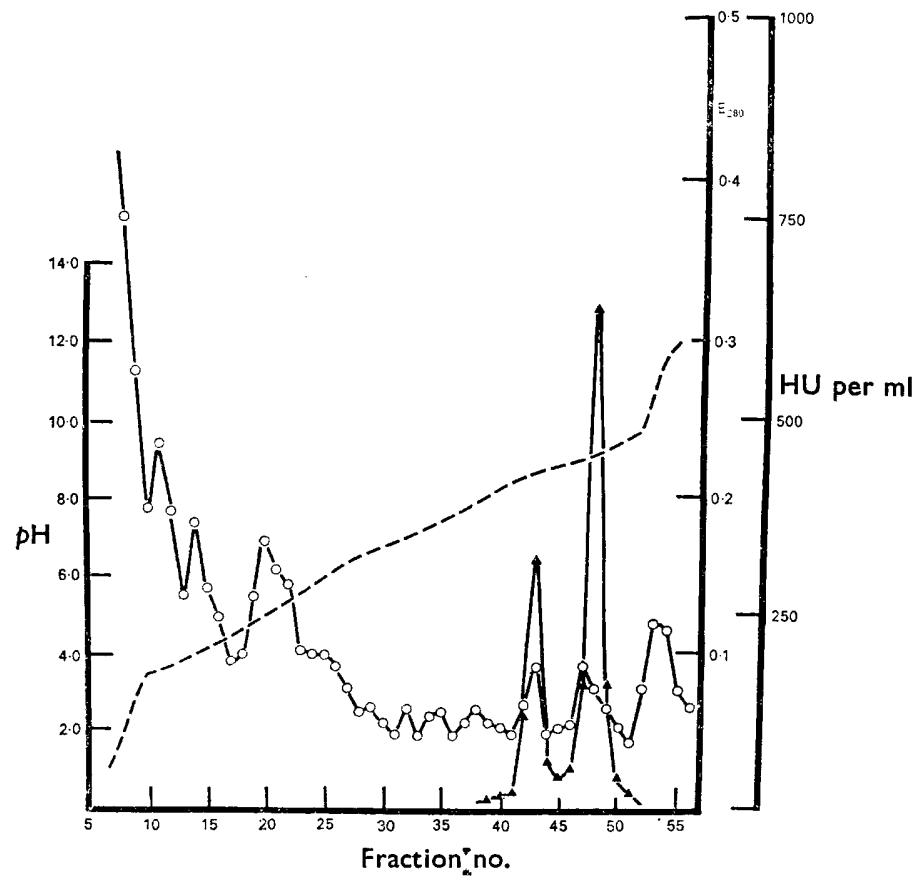

Fig. 4.-Refocusing of the component $\alpha_{\mathbf{B}}(0.74 \mathrm{mg}$ applied to 8101 column $)$ in a $p \mathrm{H}$ 3-10 gradient. $---p \mathrm{H} ; 0 \longrightarrow \mathrm{O}$ extinction at $280 \mathrm{~nm} ; \boldsymbol{\Delta} \longrightarrow \boldsymbol{\Delta}$ haemolytic activity.

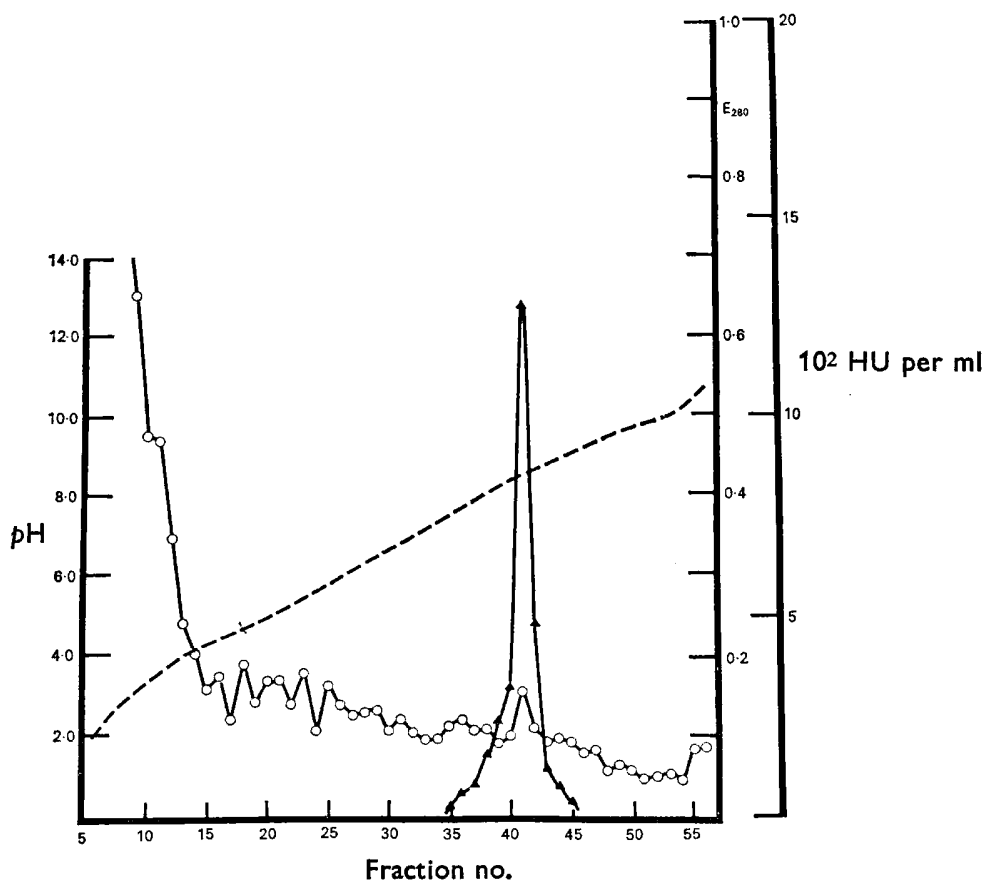

Frg. 5.-Refocusing the main component $\alpha_{\mathrm{A}}(0.79 \mathrm{mg}$ applied to 8101 column $)$ in the presence of $6 \mathrm{M}$ urea in a $p \mathrm{H}$ 3-10 gradient. - - - pH; $0-\mathrm{O}$ extinction at $280 \mathrm{~nm} ; \Delta-\Lambda$ haemolytic activity. 
Although extremely homogenous, $\alpha_{\mathrm{A}}$ preparations contained trace amounts of a large molecular weight component (approximate molecular weight $=170,000$ ); this was present to a larger extent in $\alpha_{B}$.

In the presence of $6 \mathrm{M}$ urea $\alpha_{\mathrm{A}}$ and $\alpha_{\mathrm{B}}$ shared a common main band.

\section{Discussion}

Consistent and reproducible results were obtained using the electrofocusing technique to study staphylococcal $\alpha$-toxin. The method reveals information concerning molecular heterogeneity and iso-electric points; it also allows the preparation of relatively large amounts of purified toxin in high yield. However, it is clear from our findings that several criteria must be used to assess the significance of apparently heterogeneous bacterial haemolysins.

Of the six haemolytic components detected, four had the characteristics of staphylococcal $\alpha$-toxin and have been designated $\alpha_{\mathrm{A}}, \alpha_{\mathrm{B}}, \alpha_{\mathrm{C}}$ and $\alpha_{\mathrm{D}}$; the remaining two were judged to be unrelated to this toxin. Although our findings agree in many respects with those of Wadström (1968), there are some differences and for this reason we decided not to use his terminology. Components $\alpha_{\mathrm{A}}(p \mathrm{I}=$ $8 \cdot 55 \pm 0.12)$ and $\alpha_{\mathrm{B}}(p \mathrm{I}=9 \cdot 15 \pm 0.07)$ are probably identical with Wadström's $\alpha-I_{a}(p I=8 \cdot 0-8 \cdot 7)$ and $\alpha-I_{b}(p I=9 \cdot 1-9 \cdot 2)$. The minor component $\alpha-\operatorname{II}(p I=6 \cdot 5-$ 7.5) described by Wadström appears to have been resolved into two components, $\alpha_{C}(p \mathrm{I}=7.36 \pm 0.03)$ and $\alpha_{\mathrm{D}}(p \mathrm{I}=6 \cdot 28 \pm 0 \cdot 11)$. The most acidic haemolytic peak ( $p \mathrm{I}=4 \cdot 32 \pm 0 \cdot 24)$ which corresponds approximately in position to the $\alpha$-III ( $p \mathrm{I}=4 \cdot 5-5 \cdot 5)$ of Wadström could not be designated as a form of staphylococcal $\alpha$-toxin by the criteria used by us. On the same basis, the most cationic component $(p \mathrm{I}=10.01 \pm 0.05)$ must be considered as distinct from the $\alpha$-toxin. The highly cationic nature of this haemolysin suggests that it corresponds to staphylococcal $\delta$-toxin which is known to focus between $p \mathrm{H} 9.5$ and 10.0 (Kreger et al., 1971; Möllby and Wadström, 1970).

Refocusing experiments clearly indicate that components $\alpha_{A}$ and $\alpha_{B}$ show reversible "interconversion". Disk-gel electrophoresis studies confirmed that $\alpha_{\mathrm{A}}$ and $\alpha_{\mathrm{B}}$ were related proteins and in the presence of SDS the main band was found to have a molecular weight of 36,000 . This is in good agreement with the value of 33,000 obtained by Bernheimer (1970) for the subunit of staphylococcal $\alpha$-toxin.

In contrast with the findings of Wadström, the $\alpha_{\mathrm{A}}$ component, when refocused in 6M urea, gave a single haemolytic peak. This agreed with the electrophoretic studies in urea.

Basically there are three possible mechanisms that could account for multiple forms of the type described in this paper: $(a)$ ligand formation between proteins and small molecules, $(b)$ aggregation involving protein-protein interactions and (c) the existence of more than one stable conformation of the protein. It is known that staphylococcal $\alpha$-toxin can exist in at least three physical states, namely $\alpha_{3 \mathrm{~s}}, \alpha_{12 \mathrm{~s}}$ and an insoluble aggregate (Arbuthnott et al., 1967). Freer, Arbuthnott and Bernheimer (1968) have shown that $\alpha_{3 \mathrm{~s}}$, on interaction with biological membranes, is converted to $\alpha_{12 \mathrm{~s}}$. The $\alpha_{12 \mathrm{~s}}$ form contains six subunits 


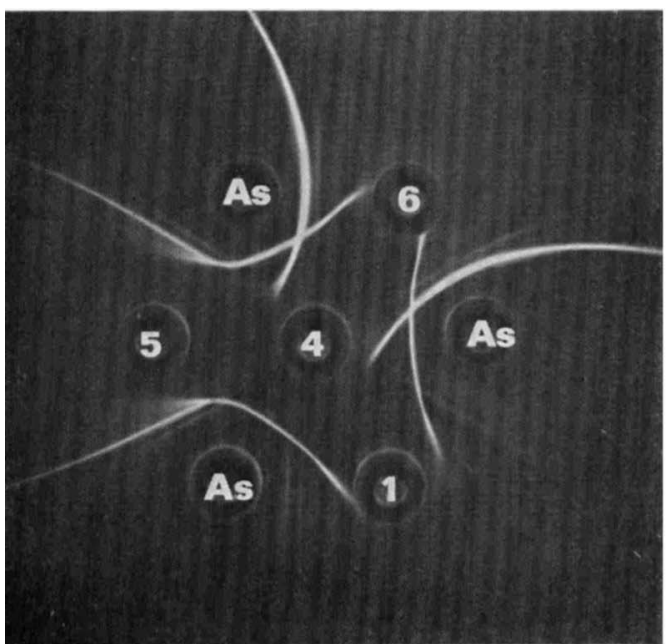

FIG. 2a.-Agar-gel diffusion pattern demonstrating the antigenic relationship of components $1,4,5$ and 6. As = Standard antiserum CPP76/63; $1=\mathrm{com}-$ ponent $1(p \mathrm{I}=4 \cdot 32 \pm 0 \cdot 24) ; 4=$ component $4(p \mathrm{I}=$ $8 \cdot 55 \pm 0 \cdot 12) ; 5=$ component $5(p \mathrm{I}=9 \cdot 15 \pm 0 \cdot 07)$; and $6=$ component $6(p \mathrm{I}=10 \cdot 01 \pm 0 \cdot 05)$.

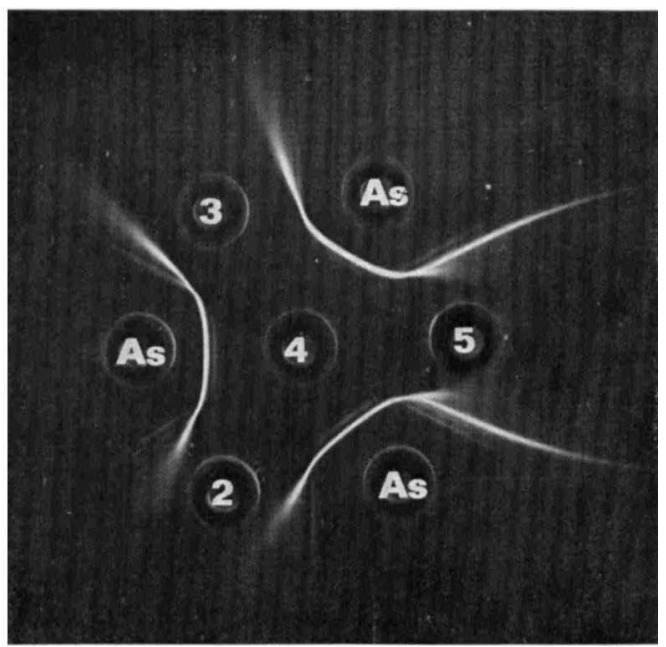

FIG. 2b.-Agar-gel diffusion pattern demonstrating the antigenic relationship of components $2,3,4$ and $5 . \quad$ As $=$ Standard antiserum CPP76/63; $2=$ component $2(\mathrm{pI}=6 \cdot 28+0 \cdot 11) ; 3=$ component 3 $(p \mathrm{I}=7 \cdot 36 \pm 0 \cdot 03) ; 4=$ component $4(p \mathrm{I}=8 \cdot 55 \pm$ $0 \cdot 12)$; and $5=$ component $5(p \mathrm{I}=9 \cdot 15 \pm 0 \cdot 07)$.

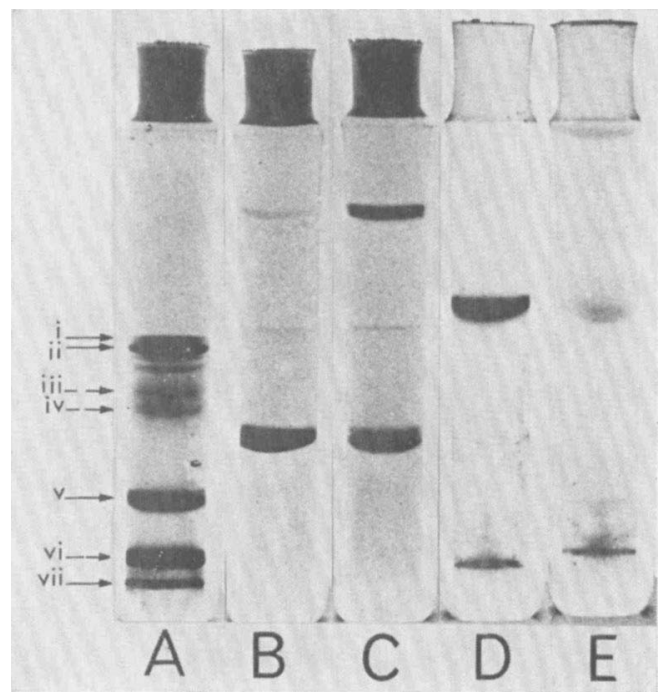

FitG. 6.-Polyacrylamide-gel electrophoresis of staphylococcal $\alpha$-toxin (the $\alpha_{A}$ and $\alpha_{B}$ components used in these experiments were obtained by refocusing $\alpha_{\mathrm{A}}$ preparations). For comparison all separating gels contain acrylamide and $\mathrm{NN}^{\prime}$-methylenebisacrylamide at concentrations of $11 \cdot 7$ per cent. and $0 \cdot 153$ per cent. $(\mathrm{w} / \mathrm{v})$ respectively (mechanically strengthened stacking gels in the SDS system are opaque and contain a negligible percentage of the total staining material). A. Marker proteins in SDS system (i) artefact band (ii) bovine serum albumin (iii) ovalbumin (iv) hexokinase (v) chymotrypsinogen (vi) myoglobin (vii) cytochrome $c$. B. $\alpha_{\mathrm{A}}$ component in SDS system. C. $\alpha_{B}$ component in SDS system. D. $\alpha_{A}$ component in urea-gel system. E. $\alpha_{B}$ component in urea-gel system. 
and appears as a ring-like aggregate. It is possible therefore that the minor components $\alpha_{\mathrm{B}}, \alpha_{\mathrm{C}}$ and $\alpha_{\mathrm{D}}$ may represent intermediates between the $\alpha_{3 \mathrm{~S}}$ and $\alpha_{12 \mathrm{~S}}$ forms of staphylococcal $\alpha$-toxin. The evidence so far available does not allow us to decide which of the three mechanisms mentioned above is operating. Further information including the determination of the molecular weight of each component and its amino acid composition is necessary.

Studies relating to the mode of action of bacterial toxins are increasingly concerned with events occurring at the molecular level. It is our belief that a detailed knowledge of the structure of bacterial toxins is fundamental to progress in this field.

\section{SUMMARY}

Electrofocusing resolved six distinct haemolytic components in crude ammonium sulphate-precipitated staphylococcal $\alpha$-toxin. Four of these had the properties of staphylococcal $\alpha$-toxin as judged by several criteria and were designated $\alpha_{\mathrm{A}}(p \mathrm{I}=8.55 \pm 0.12) ; \alpha_{\mathrm{B}}(p \mathrm{I}=9.15 \pm 0.07) ; \alpha_{\mathrm{C}}(p \mathrm{I}=7.36 \pm 0.03)$; $\alpha_{D}(p I=6.28 \pm 0.11) ; 85-95$ per cent. of the recovered activity was found as the $\alpha_{A}$ component. Reversible interconversion of $\alpha_{A}$ and $\alpha_{B}$ was demonstrated and these forms showed similar patterns in disk-gel electrophoresis; each showed a main band having a molecular weight of 36,000 and a second band having a molecular weight of 170,000 . In the presence of $6 \mathrm{M}$ urea $\alpha_{\mathrm{A}}$ yielded a single haemolytic component having a $p I$ of $8 \cdot 50$, and electrophoresis of $\alpha_{A}$ and $\alpha_{B}$ in urea revealed a single main band.

The authors gratefully acknowledge the skilled technical assistance of Miss Adrienne Cox. The work was partly supported by grants from The Royal Society, the Scottish Home and Health Department, and the Medical Research Council.

\section{REFERENCES}

Arbuthnott, J. P., Freer, J. H., ANd Bernheimer, A. W. 1967. Physical states of staphylococcal $\alpha$-toxin. J. Bact., 94, 1170.

Bernheimer, A. W. 1970. In Microbial toxins, ed. by S. J. Ajl, S. Kadis and T. C. Montie, New York, vol. 1, p. 183.

Bernheimer, A. W., Grushoff, Phyllis, ANd Avigad, Lois S. 1968. Isoelectric analysis of cytolytic bacterial proteins. J. Bact., 95, 2439.

BERNHEIMER, A. W., AND SCHWARTZ, LoIs L. 1963. Isolation and composition of staphylococcal alpha toxin. J. Gen. Microbiol., 30, 455.

Davis, B. J. 1964. Disc electrophoresis II. Method and application to human serum proteins. Ann. N.Y. Acad. Sci., 121, 404.

De Vito, E., AND SANTomé, J. A. 1966. Disc electrophoresis of proteins in the presence of sodium dodecyl sulphate. Experientia, 22, 124.

FREER, J. H., ARBUTHNOTT, J. P., AND BERNheIMER, A. W. 1968. Interaction of staphylococcal $\alpha$-toxin with artificial and natural membranes. J. Bact., 95, 1153.

Kreger, A. S., Kim, K., Zaboretzky, F., AND Bernheimer, A. W. 1971. Purification and properties of staphylococcal delta haemolysin. Infection Immun., 3, 449.

Lowry, O. H., Rosebrough, Nira J., FarR, A. L., AND Randall, Rose J. 1951. Protein measurement with the Folin phenol reagent. J. Biol. Chem., 193, 265.

MÖLlBY, R., AND WADSTRÖM, T. 1970. Studies on haemolysins from Staphylococcus aureus by the method of isoelectric focusing. In Protides of the biological fluids. Proceedings of the 17th colloquium, Bruges, 1969, ed. by H. Peeters, Oxford, p. 465. 
Neville, D. M., JR 1967. Fractionation of cell membrane protein by disc electrophoresis. Biochim. biophys. Acta, 133, 168.

REYNOLDS, JACQUELINE A., AND TANFORD, C. 1970. Binding of dodecyl sulfate to proteins at high binding ratios. Possible implications for the state of proteins in biological membranes. Proc. Natn. Acad. Sci. USA, 66, 1002.

Shapiro, A. L., ViÑuela, E., AND MaIzel, J. V., JR 1967. Molecular weight estimation of polypeptide chains by electrophoresis in SDS-polyacrylamide gels. Biochem. Biophys. Res. Commun., 28, 815.

SMYth, C. J., AND ARBUTHNotT, J. P. 1969. Isoelectric focusing of Clostridium perfringens $\alpha$ - and $\theta$-toxins. J. Gen. Microbiol., 59, Pv.

Sugahara, T., AND OHSAKa, A. 1970. Two molecular forms of Clostridium perfringens $\alpha$-toxin associated with lethal, hemolytic and enzymatic activities. Jap.J. Med.Sci. Biol., 23, 61 .

WadSTRöm, T. 1968. Studies on extracellular proteins from Staphylococcus aureus. IV. Separation of $\alpha$-toxin by isoelectric focusing. Biochim. biophys. Acta, 168, 228. 